\title{
Time perspective and self-control: metacognitive management of time is important for efficient self-regulation of behavior
}

\author{
Magdalena Mucha ${ }^{B, C, D, E, F}$, Magdalena Wiśniewska ${ }^{B, C, D, E, F}$, Edward Nęcka (D) A,C,D,E,F,G \\ Institute of Psychology, Jagiellonian University, Krakow, Poland
}

\section{BACKGROUND}

The way people perceive time is interesting in itself but also as a predictor of social, cognitive, and affective aspects of behavior. It is also a correlate of important psychological traits.

\section{PARTICIPANTS AND PROCEDURE}

In this study, we investigated associations between psychometrically assessed self-control and metacognitive processes involved in time perspective (TP). Time perspective is defined as the engagement of temporal frames for better understanding the flow of events and personal experiences. Executive control and fluid intelligence were assessed as possible mediators of the investigated relationship. Participants $(N=150)$ completed the Temporal MetaCognition Scale (TMCS), Raven's Advanced Progressive Matrices (RAPM) and two inhibitory control tasks: the Stroop and Stop Signal Task (SST). Self-control was measured with three questionnaires: NAS-50, NAS-40, and the Self-Control Scale (SCS).

\section{RESULTS}

Temporal metacognition was found to be associated with self-control, but not with executive control and fluid intelligence. Two TMCS dimensions (Goal-oriented Metatemporal Interconnectedness, Metacognitive Temporal Control) were important positive predictors of self-control, whereas the third dimension (Cognitive Reconstruction of the Past) was a weak negative predictor.

\section{CONCLUSIONS}

These findings support the hypothesis that metacognitive processes involved in time perspective may help to exert control over one's own behavior. The most important predictor of self-control is the ability to consider situations from various time perspectives.

\section{KEY WORDS}

self-control; self-regulation; temporal metacognition; time perspective; inhibitory control; executive functions; fluid intelligence

CORRESPONDING AUTHOR - Prof. Edward Nęcka, Institute of Psychology, Jagiellonian University, 6 Ingardena Str., 30-060 Krakow, Poland, e-mail: edward.necka@uj.edu.pl

Authors' contribution - A: Study design · B: Data collection · C: Statistical analysis · D: Data interpretation ·

E: Manuscript preparation · F: Literature search · G: Funds collection

TO CITE This ARTICLE - Mucha, M., Wiśniewska, M., \& Nęcka, E. (2020). Time perspective and self-control: metacognitive management of time is important for efficient self-regulation of behavior. Current Issues in Personality Psychology, $8(2), 83-91$. 


\section{BACKGROUND}

Self-control is the ability to initiate, maintain, and regulate one's own goal-directed behavior despite internal impulses, external pressures, or tendency to respond automatically (Baumeister \& Tierney, 2011; Kotabe \& Hofmann, 2015). It is one of the most powerful and adaptive human traits. A high level of self-control predicts better academic performance, efficient impulse control, fewer eating disorder symptoms, and lack of alcohol or other substance addiction problems (Storey, 1999). Self-controlling people are likely to save their money (Romal \& Kaplan, 1995) and make desirable partners in relationships (Tangney, Baumeister, \& Boone, 2004). They also tend to take a constructive approach to anger management and avoid engaging themselves in self-directed aggression (Tangney et al., 2004). Benefits of self-control have been confirmed not only in correlational studies but also in the longitudinal approach. For instance, Moffitt et al. (2011) demonstrated that self-control in childhood predicts physical health, substance addiction, socioeconomic status, and criminal offending outcomes in adolescence and adulthood. Other researchers determined the predictive value of children's ability to delay gratification for both personal and social functioning in later years of life (e.g., Casey et al., 2011; Mischel, Shoda, \& Rodriguez, 1989; Shoda, Mischel, \& Peake, 1990). Taking into account the significance of self-control for human life, it is important to know the cognitive underpinnings of this trait. In this study, we focus on one specific area of cognition, called time perspective. We also take into account executive control and general fluid intelligence as possible mediators of this relationship.

\section{TIME PERSPECTIVE AS A PSYCHOLOGICAL TRAIT}

Time perspective (TP) can be defined as "the often nonconscious process whereby the continual flows of personal and social experiences are assigned to temporal categories, or time frames, that help to give order, coherence, and meaning to those events" (Zimbardo \& Boyd, 1999, p. 1271). Zimbardo and Boyd (1999) developed a scale to measure TP, called the Zimbardo Time Perspective Inventory (ZTPI), which consists of five dimensions: Past Negative (PN), Past Positive (PP), Present Fatalistic (PF), Present Hedonistic $(\mathrm{PH})$, and Future (F). PN reflects the focus on negative personal experiences and an aversive view of the past, whereas PP is related to a sentimental and optimistic view of the past. PH reflects an orientation for immediate rewards, impulsivity, difficulties with delay of gratification, and risk-taking. PF is related to powerlessness, a helpless attitude towards life, and the inability to change the inevitability of the future.
F is characterized by planning activities to achieve future goals.

Baird, Webb, Martin, and Sirois (2017) suggested that individuals might develop a bias towards one particular TP more than the others. Hence, TP may be understood as a relatively stable individual trait. Dominant TP can influence one's thoughts, decisionmaking, and behavior. Future orientation is associated with responsible financial management, health behaviors, and academic achievements, whereas Present is related to gambling (Hodgins \& Engel, 2002) and low academic achievement (Baird et al., 2017). On the other hand, Present tends to be associated with wellbeing and positive affectivity (Przepiorka, Sobol-Kwapinska, \& Jankowski, 2016). Future TP was found to be negatively correlated with risky driving and substance abuse, whereas Present was positively associated with such tendencies (Zimbardo \& Boyd, 1999). Moreover, PP is related to health-protective behavior and academic achievements, whereas PN might be associated with alcohol consumption, unhealthy eating, and problematic Internet use (Baird et al., 2017).

The above-mentioned findings may be put into question because ZTPI suffers from low reliability. Although the original paper by Zimbardo and Boyd (1999) reports acceptable values of internal consistency, later studies revealed serious reliability problems (Worrell \& Mello, 2007), particularly in the samples investigated outside the USA (e.g., Akirmak, 2019; Skogen \& Nesvåg, 2019). Moreover, confirmatory factor analysis shows poor indices of fit concerning the original five-factor structure of ZTPI (Worrell \& Mello, 2007). Being aware of these problems, we decided to use an alternative method of time perspective assessment in the present study.

According to Fieulaine and Martinez (2011), selfcontrol and TP might be correlated because both constructs are associated with taking into account shortand long-term consequences of one's own behavior. For instance, healthy diet, risk-taking, and substance abuse involve temporal dilemmas, due to the conflict between immediate benefits and future costs. Indeed, $\mathrm{PH}$ showed a negative correlation with the ability to delay gratification (Zimbardo \& Boyd, 1999) and positive with substance abuse (Suneja, Joseph, \& Pragyendu, 2015). Various studies also indicate that $\mathrm{PH}$ is linked to impulsivity, physical and verbal aggression (Stolarski, Zajenkowski, \& Zajenkowska, 2016), risk-taking propensity (Jochemczyk, Pietrzak, Buczkowski, Stolarski, \& Markiewicz, 2017), and procrastination (Sirois, 2014). Persons scoring high on F tend to make connections between their current behavior and future goals; they also attach importance to these behaviors, ascribe value to their goals and are motivated to achieve them (Avci, 2013). Furthermore, F showed a positive correlation with physical exercise and good health (Griva, Tseferidi, \& Anagnostopoulos, 2015), as well as the ability to delay gratification 
and apply effective self-regulation learning strategies (Avci, 2013). A low level of $\mathrm{F}$ is linked to procrastination (Sirois, 2014), Internet addiction (Kim, Hong, Lee, \& Hyun, 2017), substance abuse (Suneja et al., 2015), aggression (Stolarski et al., 2016), and risk-taking propensity (Jochemczyk et al., 2017). PN and PF were found to be positive predictors of problematic Internet use (Chittaro \& Vianello, 2013), substance addiction (Suneja et al., 2015), heightened body mass index (BMI) (Griva et al., 2015), and aggression (Stolarski et al., 2016). PN is related to unhealthy eating and alcohol abuse, whereas individuals with high PP have less aggressive feelings and behaviors (Stolarski et al., 2016), more health-protective behaviors and higher levels of education (Baird et al., 2017).

There are also theoretical premises that suggest seeking relationships between self-control and time perspective. Self-control involves managing conflicts between values and goals, and consequently between behavioral tendencies, tactics, and strategies (Kotabe \& Hofmann, 2015; Scholer \& Higgins, 2010). Individuals with high $\mathrm{F}$ are more likely to overcome such conflicts because they are able to set appropriate plans based on their long-term goals and to apply strategies that are helpful in their attainment (Taylor \& Wilson, 2016). People with low F, on the other hand, are less likely to resist temptations or strive for their goals in spite of obstacles because they tend to procrastinate; they also demonstrate difficulties in delaying of gratification. Stanescu and Iorga (2015) showed that self-control is positively related to $\mathrm{F}$ and negatively to $\mathrm{PN}$ and PF. The above-mentioned findings suggest that persons with high Future TP tend to exert strong self-control, whereas people with high Present tend to demonstrate poor self-control (Kim et al., 2017).

\section{METACOGNITION IN TIME PERSPECTIVE}

Zimbardo and Boyd (1999) described the optimal TP profile, which they labeled a balanced time perspective (BTP). The authors defined BTP as a combination of high PP, moderately high $\mathrm{F}$ and $\mathrm{PH}$, and low PN and PF. BTP was found to be positively linked to health and quality of life (Oyanadel \& Buela-Casal, 2014), as well as life satisfaction, optimism, and selfesteem (Sobol-Kwapińska \& Jankowski, 2016). BTP has been found to predict less problematic use of alcohol in adulthood (McKay, Andretta, Magee, \& Worrell, 2014). It is also positively related to retirement planning and positive mood, but negatively to stress, depression, anxiety, and negative mood (Mooney, Earl, Mooney, \& Bateman, 2017).

Zajenkowski, Stolarski, Witowska, Maciantowicz, and Łowicki (2016b) suggested that BTP is a contentspecific type of mental ability, so cognitive resources might be necessary to use it effectively. Their results actually showed a positive relationship between ex- ecutive control and BTP, which turned out to be fully mediated by fluid intelligence. They suggested that BTP might be a precondition of effective switching between TPs in response to situational demands.

According to Stolarski and Witowska (2017), conscious self-regulation is at the core of one's TP. The authors suggest that metacognitive processes might be necessary for developing an optimal TP profile, especially for the ability to switch between different TPs in response to changing situational demands. The authors specified three dimensions of temporal metacognition: Metacognitive Temporal Control (MTC), Cognitive Reconstruction of the Past (CRP) and Goaloriented Metatemporal Interconnectedness (GMI). MTC reflects self-efficacy in exerting conscious control over one's current TP, the effectiveness in taking a particular TP desired in a present situation, the ability to manage one's temporal focus, and inhibition of unwanted TPs. CRP reflects the ability to reinterpret one's memories, including modification of one's perceptions of the past. GMI reflects the ability to connect different TPs and consider situations from various TPs. Temporal metacognition is positively related to BTP and life satisfaction (Stolarski \& Witowska, 2017). Furthermore, the authors suggest that temporal metacognition emerges from more general metacognitive features, such as executive functions.

Existing evidence suggests that self-control is associated with TP. However, the relatively new approach offered by Stolarski and Witowska (2017) has not been explored empirically yet. In the current study, we aimed to examine whether the three dimensions of temporal metacognition are related to various measures of self-control. We also included instruments pertaining to cognitive control and fluid intelligence, for two reasons. Firstly, executive control is believed to act as the cognitive substrate of behaviorally observed self-control (e.g., Hofmann, Schmeichel, \& Baddeley, 2012), although the existing evidence is far from clear (e.g., Nęcka, Gruszka, Orzechowski, Nowak, \& Wójcik, 2018). Taking into account the cognitive dimension seemed worth consideration, the more so that executive functioning is investigated with objective experimental procedures rather than self-reports. Secondly, there are empirical findings (Zajenkowski, Stolarski, Maciantowicz, Malesza, \& Witowska, 2016a; Zajenkowski et al., 2016b) according to which both general intelligence and executive control are implicated in the time perspective, either directly or through some sort of mediation.

\section{PARTICIPANTS AND PROCEDURE}

\section{PARTICIPANTS}

The sample consisted of 150 Polish participants, 110 women and 40 men, aged from 18 to 36 years 
$(M=23.52, S D=3.53)$. Online posters were displayed on websites inviting members of the public to take part in the study. Participants were asked to appear in pairs of friends or acquaintances who had known one another for at least six months. This precondition was necessary to allow the administration of the informant version of self-control questionnaire (NAS-40, see section 2.2.1). Assessment sessions took place in the Psychology Department laboratory, which is equipped with separate boxes, desktop computers, and headphones. Participants were tested in groups consisting of two to eight persons. They were financially compensated for their time with PLN 60 (equivalent to $€ 14$ ). The duration of the study was about three hours and a half, with a twenty-minute break in the middle.

\section{MEASURES}

The present study was part of broader psychometric research in which participants were investigated with several different questionnaires, cognitive tasks, and intelligence tests. Only measures significant for this study are described below.

\section{Self-control}

NAS-50 (Nęcka et al., 2016) consists of 50 items, 10 on each of five dimensions: Initiative and Persistence (IP), Proactive Control (PC), Switching and Flexibility (SF), Inhibition and Adjournment (IA), Goal Maintenance (GM). IP measures the motivation to pursue goals in due time, the ability to set goals and refrain from the tendency to respond reactively. PC reflects goal-directed behavior, the ability of proper planning, dividing actions into sub-actions and taking into account possible obstacles. SF measures the ability to switch between tasks or actions and avoid perseveration. IA reflects the ability to inhibit or delay competing tendencies. GM measures the ability to remember one's plans and goals and pursue them according to a time schedule. The validation study (Nęcka et al., 2016) proved that NAS-50 is a reliable assessment tool (Cronbach's $\alpha=.86$, ICC $=.94$ ).

$N A S-40$ is a third person version of the self-control scale, which was created as a mutation of NAS50 by replacing grammatical forms of its items and rejecting items not appropriate for the third person (Nęcka et al., 2016). It includes 40 items, to be completed by a person who knows the relevant participant well. Its internal reliability is also good enough $(\alpha=.84$, ICC $=.92)$ (Nęcka et al., 2016). Since participants were invited to come in pairs of friends or acquaintances who knew one another, NAS-40 could be completed mutually in pairs. In this way, every participant served as an informant and as an object of rating as well.
The Self-Control Scale (SCS; Pilarska \& Baumeister, 2018; Tangney et al., 2004) consists of 36 items encompassing different kinds of self-control, including control over thoughts, emotions, impulse control, performance regulation, and habit breaking. The participants completed the Polish translation of the scale, which is characterized by a satisfactory level of reliability (Pilarska \& Baumeister, 2018).

\section{Executive control}

Stroop Task. The numerical version of the Stroop Task, which required counting digits and ignoring their meaning, was used (Fox et al., 1971; Chuderski, Taraday, Nęcka, \& Smoleń, 2012). The screen showed three, four, five, or six exemplars of a digit drawn from the set: $3,4,5,6$. In congruent trials (60) the number of stimuli was in concord with the digits, though in incongruent trials (90) the former and the latter differed. In neutral condition (60) the stimuli were not digits. The instruction was to avoid reading a digit and to press a response key that was assigned to a presented number of stimuli. The number of correct responses and the average response time in each condition were registered.

Stop Signal Task. Participants also performed the Stop Signal Task (SST; Logan, 1994) modified by Verbruggen, Logan, and Stevens (2008). Pictures of an arrow pointing left or right appeared on the screen and participants were asked to press the left or right arrow key according to the direction of the displayed arrow. The stimuli were presented randomly, each with $50 \%$ probability. Participants were instructed to be fast and correct but refrain from the response when an auditory stop signal was presented. After successful inhibition, the interval between go and stop stimuli became $50 \mathrm{~ms}$ longer, and after unsuccessful inhibition, $50 \mathrm{~ms}$ shorter. The stop-signal delay was set to $250 \mathrm{~ms}$ at the start and remained within the range $50 \mathrm{~ms}$ to $1150 \mathrm{~ms}$. The shorter the SSRT (stop signal reaction time), the better is one's ability to inhibit the unnecessary response.

\section{Fluid intelligence}

Raven's Advanced Progressive Matrices (APM; Raven, Court, \& Raven, 1983) is a non-verbal test of abstract reasoning regarded as an estimate of fluid intelligence. It consists of 48 items (12 in training set I, 36 in assessing set II). In this study, participants completed every second item, because of the necessity to prevent fatigue. Time limits were two and 15 minutes for Sets I and II, respectively.

\section{Time perspective}

The Temporal MetaCognition Scale (TMCS; Stolarski \& Witowska, 2017) consists of 26 items organized 
into three dimensions: Metacognitive Temporal Control (MTC), Cognitive Reconstruction of the Past (CRP) and Goal-oriented Metatemporal Interconnectedness (GMI). MTC measures self-efficacy in exerting conscious control over one's current TP. CRP reflects the ability to reconstruct one's memories of the past. GMI measures the ability to consider situations from various TPs and take advantage of using past experiences and mental simulations of the future. The TMCS questionnaire shows acceptable indices of internal consistency, with Cronbach's $\alpha$ ranging between .78 and .88 , depending on the subscale (Stolarski \& Witowska, 2017).

\section{RESULTS}

First, we checked the reliability of the TMCS questionnaire in this particular study. The Cronbach's $\alpha$ coefficient values were found to be as follows: .83 (MTC), .73 (CRP), .79 (GMI), and .80 (full scale). Thus, the internal consistency measures of this instrument seem satisfactory.Descriptive statistics are provided in Table 1. The means and the standard deviations of NAS-50, NAS-40, and SCS are similar to the results of the validation studies (Nęcka et al., 2016; Pilarska \& Baumeister, 2018). Table 2 presents correlation coefficients between TMCS and self-control. All measures of self-control were found to be inter-correlated. The correlation between NAS-50 and NAS-40 was also significant but not strong. However, its strength is similar to the results reported in the validation studies (Nęcka et al., 2016). Importantly, various selfcontrol measures were significantly associated with TMCS in general as well as with some of its subscales. The results indicate that GMI was positively correlated with all measures of self-control. MTC correlated positively with NAS-50 and SCS, but it was not associated with NAS-40. CRP was not found to be related to any measure of self-control.

Because of the significant correlation between GMI and MTC, partial correlations were carried out.
Table 3 shows that correlation coefficients between GMI and self-control measures remained significant after controlling for MTC and CRP variables. While controlling for GMI and CRP, MTC was still significantly and positively correlated with NAS-50 and SCS, although it was not related to NAS-40. Notably, CRP showed a weak negative correlation with NAS-50 and SCS, after controlling for GMI and MTC variables.

Table 1

Descriptive statistics

\begin{tabular}{lrrc}
\hline Scale & $M$ & $S D$ & Range \\
\hline NAS-50 & 167.37 & 20.77 & 110 \\
$\quad$ Proactive Control & 37.17 & 5.54 & 28 \\
$\quad$ Goal Maintenance & 38.26 & 5.76 & 28 \\
$\quad$ Initiative and & 27.86 & 8.52 & 39 \\
$\quad$ Persistence & & & \\
$\quad \begin{array}{l}\text { Inhibition and } \\
\text { Adjournment }\end{array}$ & 26.77 & 6.33 & 33 \\
$\quad$ Switching and & 37.32 & 6.04 & 30 \\
$\quad$ Flexibility & 137.97 & 18.00 & 95 \\
NAS-40 & 112.83 & 17.82 & 92 \\
SCS & 91.31 & 10.23 & 50 \\
TMCS & 32.11 & 6.89 & 36 \\
$\quad \begin{array}{l}\text { Metacognitive } \\
\text { Temporal Control }\end{array}$ & & & \\
$\begin{array}{l}\text { Cognitive } \\
\text { Reconstruction of } \\
\text { the Past }\end{array}$ & 22.54 & 3.52 & 18 \\
$\begin{array}{l}\text { Goal-oriented } \\
\text { Metatemporal }\end{array}$ & & & \\
Interconnectedness & 36.65 & 5.31 & 27 \\
APM & 15.82 & 3.72 & 22 \\
\hline
\end{tabular}

Table 2

Correlations between TMCS and self-control

\begin{tabular}{|c|c|c|c|c|c|c|}
\hline & NAS-50 & SCS & NAS-40 & TMCS & GMI & MTC \\
\hline SCS & $.75^{* *}$ & & & & & \\
\hline NAS-40 & $.29^{* *}$ & $.30 * *$ & & & & \\
\hline TMCS & $.50^{* *}$ & $.43^{* *}$ & $.18^{*}$ & & & \\
\hline GMI & $.53^{* *}$ & $.52^{* *}$ & $.24^{* *}$ & $.68^{* *}$ & & \\
\hline MTC & $.39^{* *}$ & $.30 * *$ & .18 & $.77^{* *}$ & $.19^{*}$ & \\
\hline CRP & -.11 & -.13 & .12 & $.38^{* *}$ & .09 & -.17 \\
\hline
\end{tabular}

Note. GMI - Goal-oriented Metatemporal Interconnectedness, MTC - Metacognitive Temporal Control, CRP - Cognitive Reconstruction of the Past. ${ }^{*} p<.05,{ }^{* *} p<.01$. 
Table 4 shows that TMCS was significantly associated with all NAS-50 dimensions. GMI correlated significantly positively with all NAS-50 dimensions, particularly strongly with Proactive Control and relatively strongly with Initiative and Persistence. MTC was associated with almost all NAS-50 dimensions. The only exception was the lack of association between MTC and Proactive Control. CRP correlated weakly and negatively only with Goal Maintenance and Inhibition and Adjournment.

In order to assess the impact of TMCS dimensions on self-control, three linear regression models were constructed. TMCS dimensions (GMI, MTC, CRP) were the independent variables, while the dependent variables were the scores of NAS-50 in the first, SCS in the second, and NAS-40 in the third model. All regression models obtained an adequate fit. The first model was significant $(F(3,146)=30.48, p<.001$ with $R^{2}=.37$ ), implying that $37.2 \%$ of the variance in NAS- 50 score was explained by all TMCS dimensions. GMI and MTC were significant positive predictors, whereas CRP was a significant negative predictor of NAS$50(\beta=.48, p<.001 ; \beta=.30, p<.001 ; \beta=-.14, p<.05$, respectively). The second model revealed similar results $\left(F(3,145)=24.50, p<.001\right.$, with $\left.R^{2}=.32\right)$, implying that $32.3 \%$ of the variance in the SCS score is explained by TMCS dimensions. GMI $(\beta=.49, p<.001)$ and MTC $(\beta=.21, p<.01)$ were significant positive predictors of SCS, whereas CRP was a significant negative predictor $(\beta=-.17, p<.05)$. The third re-

Table 3

Partial correlations between TMCS dimensions and self-control

\begin{tabular}{lccc}
\hline Scale & NAS-50 & NAS-40 & SCS \\
\hline GMI & $.52^{* *}$ & $.23^{* *}$ & $.51^{* *}$ \\
MTC & $.35^{* *}$ & -.25 & $.24^{* *}$ \\
CRP & $-.18^{*}$ & .10 & $-.20^{*}$ \\
\hline
\end{tabular}

Note. GMI - Goal-oriented Metatemporal Interconnectedness, MTC - Metacognitive Temporal Control, CRP - Cognitive Reconstruction of the Past. ${ }^{*} p<.05,{ }^{* *} p<.01$. gression model was also significant $(F(3,145)=3.47$, $p<.05$, with $R^{2}=.05$ ). However, only GMI emerged as a significant predictor of NAS-40 $(\beta=.23, p<.01)$.

In order to examine whether temporal metacognition was associated with fluid intelligence and cognitive control, correlational analyses were conducted. The results indicate that correlations between TMCS and APM ranged between -.05 and .06, depending on the subscale, and were statistically insignificant. There were also no significant correlations between TMCS and response inhibition. The interference effect from the Stroop Task was not correlated significantly with any dimension of TMCS. These correlations ranged from $r=.04$ to $r=.08(p>.05)$. We also did not find any significant correlations between TMCS dimensions and inhibitory control, measured with Stop Signal Reaction Time $(-.02<r<-.09$, $p>.05)$. Additionally, neither APM nor inhibitory control measures correlated with variables pertaining to self-control $(-.13<r<.16, p>.05)$. It must be underscored that we decided to include the measures of general intelligence and executive control as potential mediators of the relationship between time perspective (independent variable) and self-control (output variable). Since potential mediators did not correlate with the independent variable or the output variable, mediation analysis was pointless (Fairchild \& McDaniel, 2017).

\section{DISCUSSION}

The aim of this study was to examine possible relationships between temporal metacognition and selfcontrol, fluid intelligence, and cognitive control. We found that self-control correlated positively with goaloriented metatemporal interconnectedness (GMI) and metacognitive temporal control (MTC), though negatively with cognitive reconstruction of the past (CRP). Moreover, the results indicate that GMI was the strongest and CRP the weakest predictor of selfcontrol. Fluid intelligence and executive control did not show any relationship with self-control and time perspective.

Table 4

Correlations between TMCS and NAS-50 dimensions

\begin{tabular}{lccccc}
\hline & $\begin{array}{c}\text { Proactive } \\
\text { Control }\end{array}$ & $\begin{array}{c}\text { Goal } \\
\text { Maintenance }\end{array}$ & $\begin{array}{c}\text { Initiative and } \\
\text { Persistence }\end{array}$ & $\begin{array}{c}\text { Inhibition and } \\
\text { Adjournment }\end{array}$ & $\begin{array}{c}\text { Switching and } \\
\text { Flexibility }\end{array}$ \\
\hline TMCS & $.38^{* *}$ & $.30^{* *}$ & $.34^{* *}$ & $.20^{*}$ & $.33^{* *}$ \\
GMI & $.72^{* *}$ & $.21^{*}$ & $.44^{* *}$ & $.16^{*}$ & $.17^{*}$ \\
MTC & -.10 & $.37^{* *}$ & $.26^{* *}$ & $.25^{* *}$ & $.36^{* *}$ \\
CRP & .03 & $-.18^{*}$ & -.03 & $-.17^{*}$ & .00 \\
\hline
\end{tabular}

Note. GMI - Goal-oriented Metatemporal Interconnectedness, MTC - Metacognitive Temporal Control, CRP - Cognitive Reconstruction of the Past. ${ }^{*} p<.05,{ }^{* *} p<.01$. 
GMI reflects integration of various time perspectives, promotes their balancing, and prevents possible biases for one particular TP. It is related to Future TP, thus promoting goal achievement and effectiveness (Stolarski \& Witowska, 2017). The strong relationship between GMI and self-control seems to be entirely understandable in the light of positive associations between Future TP and self-control (Kim et al., 2017; Stanescu \& Iorga, 2015). The results suggest that individuals who are concerned with future goals prove to be better at managing their behavior. Persons scoring high on GMI might benefit from their past and present experience to achieve future goals. Therefore, the ability to switch effectively among various TPs depending on situational demands results in effective self-regulation of behavior, which can be reflected in a heightened level of psychometrically assessed self-control.

Due to the strong correlation between GMI and Proactive Control, we conducted a semantic analysis of the items from both subscales. It was found that these items typically pertain to future-oriented and goal-directed behavior, thus reflecting the emblematic feature of self-control, that is, a conflict between immediate short-term gratification and delayed longterm gain (Scholer \& Higgins, 2010). Persons with the ability to take advantage of connectedness between TPs to achieve future goals might be successful in proper planning and making decisions in accordance with their goals.

CRP reflects the inclination to change one's perception of the past, which may result in behavioral tendencies that are typical for inefficient self-control (Stolarski et al., 2016; Suneja et al., 2015). Stanescu and Iorga (2015) suggest that people who ruminate over past unpleasant experiences are less likely to manage planned behavior. Reconstruction of the past might be a defense mechanism protecting against one's own negative emotions. In this way, it is counterproductive for the process of setting long-term goals and striving for them.

Furthermore, persons scoring high on CRP might have difficulties with inhibition of irrelevant thoughts. Thus, the negative correlation of CRP with self-control becomes entirely understandable.

Stolarski and Witowska (2017) suggest that MTC should be positively associated with various aspects of self-control. The current study confirmed this assumption. MTC reflects the effectiveness in exertion of conscious control over one's current temporal horizon and inhibition of unwanted, or improper, time perspectives (TPs). Switching between tasks, avoidance of perseveration, and inhibition of improper tendencies are important components of self-control. Individuals who are effective in management of their present TP seem to be efficient in control of their behavior as well. Moreover, MTC is negatively associated with negative TPs (Stolarski
\& Witowska, 2017), which are not favorable for selfcontrol.

Contrary to previous findings, temporal metacognition appeared unrelated to inhibitory control and fluid intelligence. The research of Zajenkowski et al. (2016b) revealed that BTP was positively correlated with cognitive control and fluid intelligence ${ }^{1}$. However, the magnitude of those correlations was rather small, accounting for less than $4 \%$ of variance. Furthermore, BTP was significantly associated with performance on the Anti-saccade task only, with no relationship with another executive control task (Go/No-go). Another relevant study (Zajenkowski et al., 2016a) reports a similarly low relationship between fluid intelligence and balanced time perspective $(r=.15)$. Out of five ZTPI dimensions, only Past Negative and Present Fatalistic significantly, albeit weakly, correlated with Raven's matrices $(r=-.15$ and $r=-.21$, respectively). The lack of similar associations in the present study might stem from using different measures of TP or from the fact that correlations between ability-based and self-report indicators are usually difficult to find (Nęcka et al., 2018).

Our study suggests that greater attention should be paid to the phenomenon of conscious self-regulation of one's TP, which seems to be considerably related to self-control. In this respect, future research could consider the impact of temporal metacognition on problematic behaviors, such as procrastination, various types of addiction, risk-taking, health-related behavior, or aggression.

Finally, let us underscore some limitations of the present study. Firstly, the current research had a cross-sectional character; hence, the causal nature of the relationship between temporal metacognition and self-control could not be revealed. Secondly, both self-control and time perspective were assessed with self-report measures, which might be biased toward subjectivity. These limitations can be overcome in future studies through the application of a longitudinal approach and objective measurement tools. Future studies should also help to reveal possible moderators and mediators of the relationship between selfcontrol and time perspective.

\section{ENDNOTE}

1 The coefficients reported are negative because they refer to deviation from balanced time perspective.

\section{References}

Akirmak, U. (2019). The validity and reliability of the Zimbardo time perspective inventory in a Turkish sample. Current Psychology. https://doi.org/10.1007/ s12144-019-0153-3 
Avci, S. (2013). Relations between self-regulation, future time perspective and the delay of gratification in university students. Education, 133, 525-537.

Baird, H. M., Webb, T. L., Martin, J., \& Sirois, F. M. (2017). The relationship between time perspective and self-regulatory processes, abilities and outcomes: A protocol for a meta-analytical review. BMJ Open, 7, e017000.

Chittaro, L., \& Vianello, A. (2013). Time perspective as a predictor of problematic Internet use: A study of Facebook users. Personality and Individual Differences, 55, 989-993.

Baumeister, R. F., \& Tierney, J. (2011). Willpower: Rediscovering the greatest human strength. New York: Penguin Books.

Casey, B. J., Somerville, L. H., Gotlib, I. H., Ayduk, O., Franklin, N. T., Askren, M. K., ... \& Glover, G. (2011). Behavioral and neural correlates of delay of gratification 40 years later. Proceedings of the National Academy of Sciences, 108, 14998-15003.

Chuderski, A., Taraday, M., Nęcka, E., \& Smoleń, T. (2012). Storage capacity explains fluid intelligence but executive control does not. Intelligence, 40, 278-295.

Fairchild, A. J., \& McDaniel, H. L. (2017). Best (but oft-forgotten) practices: mediation analysis. The American Journal of Clinical Nutrition, 105, 12591271. https://doi.org/10.3945/ajcn.117.152546

Fieulaine, N., \& Martinez, F. (2011). About the fuels of self-regulation: Time perspective and desire for control in adolescents substance use. In V. Barkoukis (Ed.), The Psychology of Self-Regulation (pp. 102-121). Nova Science Publishers.

Fox, L. A., Shor, R. E., \& Steinman, R. J. (1971). Semantic gradients and interference in naming color, spatial direction, and numerosity. Journal of Experimental Psychology, 91, 59-65. https://doi.org/10.1037/ h0031850

Griva, F., Tseferidi, S. I., \& Anagnostopoulos, F. (2015). Time to get healthy: Associations of time perspective with perceived health status and health behaviors. Psychology, Health \& Medicine, 20, 25-33.

Hodgins, D. C., \& Engel, A. (2002). Future time perspective in pathological gamblers. The Journal of Nervous and Mental Disease, 190, 775-780.

Hofmann, W., Schmeichel, B. J., \& Baddeley, A. D. (2012). Executive functions and self-regulation. Trends in Cognitive Science, 16, 174-180. https:// doi.org/10.1016/j.tics.2012.01.006

Jochemczyk, Ł., Pietrzak, J., Buczkowski, R., Stolarski, M., \& Markiewicz, Ł. (2017). You only live once: present-hedonistic time perspective predicts risk propensity. Personality and Individual Differences, 115, 148-153.

Kim, J., Hong, H., Lee, J., \& Hyun, M. H. (2017). Effects of time perspective and self-control on procrastination and Internet addiction. Journal of Behavioral Addictions, 6, 229-236.
Kotabe, H. P., \& Hofmann, W. (2015). On integrating the components of self-control. Perspectives on Psychological Science, 10, 618-638.

Logan, G. D. (1994). On the ability to inhibit thought and action: A users' guide to the stop signal paradigm. In D. Dagenbach \& T. H. Carr (Eds.), Inhibitory Processes in Attention, Memory, and Language (pp. 189-239). San Diego, CA: Academic Press.

McKay, M. T., Andretta, J. R., Magee, J., \& Worrell, F. C. (2014). What do temporal profiles tell us about adolescent alcohol use? Results from a large sample in the United Kingdom. Journal of Adolescence, 37, 1319-1328.

Mischel, W., Shoda, Y., \& Rodriguez, M. I. (1989). Delay of gratification in children. Science, 244, 933-938.

Moffitt, T. E., Arseneault, L., Belsky, D., Dickson, N., Hancox, R. J., Harrington, H., Houts, R., Poulton, R., Roberts, B. W., Ross, S., Sears, M. R., Thomson, W. M., \& Caspi, A. (2011). A gradient of childhood self-control predicts health, wealth, and public safety. Proceedings of the National Academy of Sciences of the United States of America, 108, 2693-2698.

Mooney, A., Earl, J. K., Mooney, C. H., \& Bateman, H. (2017). Using balanced time perspective to explain well-being and planning in retirement. Frontiers in Psychology, 8, 1781.

Nęcka, E., Gruszka, A., Orzechowski, J., Nowak, M., \& Wójcik, N. (2018). The (in)significance of executive functions for the trait of self-control: A psychometric study. Frontiers in Psychology, 9, 1139. https://doi.org/10.3389/fpsyg.2018.01139

Nęcka, E., Wujcik, R., Orzechowski, J., Gruszka, A., Janik, B., Nowak, M., \& Wójcik, N. (2016). NAS-50 and NAS-40: New scales for the assessment of selfcontrol. Polish Psychological Bulletin, 47, 346-355.

Oyanadel, C., \& Buela-Casal, G. (2014). Time perception and psychopathology: influence of time perspective on quality of life of severe mental illness. Actas Españolas de Psiquiatría, 42, 99-107.

Pilarska, A., \& Baumeister, R. F. (2018). Psychometric properties and correlates of the Polish versions of the Self-Control Scale (SCS). Polish Psychological Bulletin, 49, 95-106. https://doi.org/10.24425/119476

Przepiorka, A., Sobol-Kwapińska, M., \& Jankowski, T. (2016). A Polish short version of the Zimbardo Time Perspective Inventory. Personality and Individual Differences, 101, 78-89. http://dx.doi.org/10.1016/ j.paid.2016.05.047

Raven, J. C., Court, J. H., \& Raven, J. (1983). Manual for Raven's Progressive Matrices and Vocabulary Scales. London: H.K. Lewis \& CoLtd.

Romal, J. B., \& Kaplan, B. J. (1995). Difference in selfcontrol among spenders and savers. Psychology: A Journal of Human Behavior, 32, 8-17.

Scholer, A. A., \& Higgins, E. T. (2010). Conflict and control at different levels of self-regulation. In R. Hassin, K. Ochsner, \& Y. Trope. (Eds.), Self 
control in society, mind, and brain (pp. 312-334). Oxford, UK: Oxford University Press.

Shoda, Y., Mischel, W., \& Peake, P. K. (1990). Predicting adolescent cognitive and self-regulatory competencies from preschool delay of gratification: Identifying diagnostic conditions. Developmental Psychology, 26, 978.

Sirois, F. M. (2014). Out of sight, out of time? A metaanalytic investigation of procrastination and time perspective. European Journal of Personality, 28, 511-520.

Skogen, J. C., \& Nesvåg, S. (2019). Factor structure of Zimbardo Time Perspective Inventory (ZTPI) in a Norwegian convenience sample. Timing and Time Perception, 7, 277-290. https://doi.org/10. 1163/22134468-20191149

Sobol-Kwapińska, M., \& Jankowski, T. (2016). Positive time: Balanced time perspective and positive orientation. Journal of Happiness Studies, 17, 1511-1528.

Stanescu, D. F., \& Iorga, M. E. (2015). An exploratory study regarding the relations between time perspective, achievement motivation and self-regulation. Management Dynamics in the Knowledge Economy, 3, 7.

Stolarski, M., \& Witowska, J. (2017). Balancing one's own time perspective from aerial view: Metacognitive processes in temporal framing. In A. Kostić, \& D. Chadee (Eds.), Time Perspective (pp. 117-141). London, UK: Palgrave Macmillan.

Stolarski, M., Zajenkowski, M., \& Zajenkowska, A. (2016). Aggressive? From time to time... Uncovering the complex associations between time perspectives and aggression. Current Psychology, 35, 506-515.

Storey, F. S. (1999). Childhood abuse and self-regulation: Risk factors for heroin addiction. Dissertation Abstracts International: Section B: the Sciences \& Engineering, 59, 3717.

Suneja, A., Joseph, J. V., \& Pragyendu (2015). Effects of the time perspectives on substance abuse. The International Journal of Indian Psychology, 3, 13-19.

Tangney, J. P., Baumeister, R. F., \& Boone, A. L. (2004). High self-control predicts good adjustment, less pathology, better grades, and interpersonal success. Journal of Personality, 72, 271-324. https:// doi.org/10.1111/j.0022-3506.2004.00263.x

Taylor, J., \& Wilson, J. C. (2016). Failing time after time: time perspective, procrastination, and cognitive reappraisal in goal failure. Journal of $A p$ plied Social Psychology, 46, 557-564.

Verbruggen, F., Logan, G. D., \& Stevens, M. A. (2008). STOP-IT: Windows executable software for the stop-signal paradigm. Behavior Research Methods, 40, 479-483.

Worrell, F. C., \& Mello, Z. R. (2007). The reliability and validity of Zimbardo Time Perspective Inventory Scores in academically talented adolescents. Educational and Psychological Measurement, 67, 487504. https://doi.org/10.1177/0013164406296985
Zajenkowski, M., Stolarski, M., Maciantowicz, O., Malesza, M., \& Witowska, J. (2016a). Time to be smart: Uncovering a complex interplay between intelligence and time perspective. Intelligence, 58, 1-9.

Zajenkowski, M., Stolarski, M., Witowska, J., Maciantowicz, O., \& Łowicki, P. (2016b). Fluid intelligence as a mediator of the relationship between executive control and balanced time perspective. Frontiers in Psychology, 7, 1844.

Zimbardo, P. G., \& Boyd, J. N. (1999). Putting time in perspective: a valid, reliable individual-differences metric. Journal of Personality and Social Psychology, 77, 1271-1288. 